\title{
Resource Boom, Industrial Structure and Economic Growth in a DSGE Model
}

\author{
Bin Liang ${ }^{1, a}$, Yiwei Lian ${ }^{2, b}$, Xiaoyi $\mathrm{Ji}^{3, \mathrm{c}}$ \\ ${ }^{1}$ School of Economic and Management, Inner Mongolia University, Huhhot, China \\ ${ }^{2}$ School of Management, Central University of Nationalities, Beijing, China \\ ${ }^{3}$ College of Economics and Management, Northeast Forestry University, Harbin,China \\ ahellobin@126.com, 'lianivy@126.com, ccdjoshua@163.com
}

Keywords: Dutch Disease, Industrial Structure, DSGE, R\&D arbitrage

\begin{abstract}
Literature of "Dutch disease" concerns about the de-industrialization induced by the resource boom. But the core model of "Dutch disease" is based on the experiences of developed countries, such as Holland and Australia. We extend the literature of "resource curse" by proposing that the initial industrial structure is an essential factor for an economy to experience a blessing or curse with a resource boom. We also draw a clear distinction between resource booms and price booms, and restrict our study on the resource boom of point source natural resources. We setup a multi-sector model with $R \& D$ arbitrage to explore a structure-upgrading transmission channel of a resource boom to illustrate that the change of industrial structures incurred by resource boom may bring "industrial bonus".
\end{abstract}

\section{Introduction}

The purpose of this study is to investigate the relationship between natural resource boom, industrial structure and economic growth in a DSGE model. Compared with developed countries, China is still in the process of the industrialization. Scholars, who study most Chinese economic issues, usually pay much attention to the industrial structure conditions. But when discussing the effect of natural resource prosperity, scholars follow the models of "resource curse", such as "Dutch disease", which is based on the facts of developed countries and pay no attention to the distinct difference between those countries.

We extend the literature by the following features: incorporate a resource-based sector in our model, which is high-tech compared to the exploitation sector that produce only primary resource products; examine the impact of a resource boom on the industrial structure and propose that industrial structure condition is an essential factor for an economy with natural abundance; make a clear distinction between resource boom and price boom: a price boom is a rise of price of natural resources, a resource boom is an increase in the stock of natural resources.

\section{Literature}

Does the resource curse really exist? If the "curse" is true, then the economies with resource abundance should leave their natural resources unexploited. We can also see many successful resource-based economies to avoid the "Dutch disease". So it is interesting to ask which factors or paths exist for resource-based economies to avoid the "curse". Some studies suggest that the "curse" can be reversed and there are some countries which are really benefit from their natural wealth, such as Botswana and Arab Emirates (Frederick Van der Ploeg, 2011). It is interesting 
to ask what factors explain the successful economic growth in the economies with a resource boom. Some studies argue that when developing countries are considered, these arguments may not be valid (Nancy C. Benjamin et al., 1989). Even when we review the history of some developed countries, coal and iron ore deposits were a prerequisite for the development of an indigenous industrial industry. The timing of the U.S. leadership in industrial production coincides with its leadership in the production of resource goods (Jean-Philippe C. Stijns, 2005). The poor performance of the Italian economy before World War I is explained by the lack of domestic coal reserves, which resulted in a backward economic structure of production .

If a resource boom maybe a "blessing" for the economy, what is the possible mechanism? There are two types of external shocks related to natural resource: a price shock (a rise of price of natural resources) and a boom shock (an increase in the stock of natural resources). Most studies focus on the price shock(Luis J. A Lvarez et al., 2011), and argue that the high volatility of world prices of natural resources is the cause of "resource curse" (Frederick Van der Ploeg and Steven Poelhekke, 2009). One the contrary, the boom shock has not been well studied (Mohamed Benkhodja, 2011). Some also propose that contrary to the standard models of "Dutch disease”, both the traded and the non-traded sector can contribute to learning which is the key factor of economic growth (Ragnar Torvik, 2001), and the non-tradable sector is crucial for the impact of a resource boom. But developing countries in the industrialization process usually have a small non-traded sector. Is it means that developing countries are doomed to suffer the "resource curse"? The purpose of this study is focus on the resource boom shock to fill the literature gap and investigate the relationship between resource boom, industrial structure and economic growth.

\section{Theoretical Model}

One of the most distinguished differences between developing and developed countries is the industrial structure. While most of literatures on the Dutch disease refer to the problem met by developed countries with a mature industrial structure, developing countries, such as China, are still under the industrialization process. Classical models of Dutch disease only incorporate three sectors: natural resource sector, manufacturing sector and non-tradable goods. In order to study the role of industrial structure in "Dutch disease", our model includes five sectors in our model: households, agriculture sectors, manufacturing sectors, resource-based sectors, and service sectors. In our model, there are two set of goods: non-tradable goods includes service goods; tradable goods includes agriculture goods, manufacturing goods, and resource-based goods.

\section{Households:}

The model considers a representative household who derives utility from two types of consumption:

$$
\sum_{t=0}^{\infty} \frac{1}{(1+\beta)^{t}}\left[a\left(c_{t}^{T}\right)^{1-\frac{1}{\sigma}}+(1-a)\left(c_{t}^{N}\right)^{1-\frac{1}{\sigma}}\right]^{\frac{\sigma}{\sigma-1}}
$$

where $c_{t}^{T}$ denotes time t consumption of tradable goods and $c_{t}^{N}$ denotes time t consumption of is the non-tradable goods, $\beta$ is the subjective discount factor, $a \in(0,1)$ is the share of different types of consumption in the utility, $\sigma \in(0, \infty)$ is the elasticity of intra-temporal substitution between tradable goods and non-tradable-goods.

It is assumed that the representative household owns all the firms and they receive the total output of the economy, and then has the following budget constraint:

$$
p_{t}^{T} c_{t}^{T}+p_{t}^{N} c_{t}^{N}=p_{t} y_{t}
$$


Where $p_{t}^{T}$ is the price of tradable goods and $p_{t}^{N}$ is the price of non-tradable goods, $y_{t}$ is the total output of the economy.

The representative household maximizes the utility function (1) subject to the budget constraint (2) and the first order conditions are as following:

$$
\begin{aligned}
c_{t}^{N} & =\frac{\left(p_{t}^{N}\right)^{-\sigma}}{\left(p_{t}^{N}\right)^{1-\sigma}+\left(p_{t}^{T}\right)^{1-\sigma}} p_{t} y_{t} \\
c_{t}^{T} & =\frac{\left(p_{t}^{T}\right)^{-\sigma}}{\left(p_{t}^{N}\right)^{1-\sigma}+\left(p_{t}^{T}\right)^{1-\sigma}} p_{t} y_{t}
\end{aligned}
$$

\section{Manufacturing sector:}

We introduce a manufacturing sector to capture the idea of Dutch disease that the wealth earned by the windfall of natural resources induces the appreciation of the real exchange rate and an ensuing contraction of the manufacturing sector. A manufactured good is part of tradable goods and a representative firm produces its manufacturing goods using two inputs: capital $k_{t}^{M}$ and labor $l_{t}^{M}$. The production function is given by:

$$
y_{t}^{M}=A_{t}^{M}\left(k_{t}^{M}\right)^{\alpha}\left(l_{t}^{M}\right)^{1-\alpha}
$$

It is assumed that labors can flow between different sectors and the wage $w_{t}$ of the economy is equal to 1 . The representative manufacturing firm maximizes the profit: $\max \Pi=p_{t}^{M} y_{t}^{M}-r k_{t}^{M}-w l_{t}^{M}$. The first order conditions are as following:

$$
l_{t}^{M}=k_{t}^{M}\left[(1-\alpha) A_{t}^{M} \frac{p_{t}^{M}}{p_{t}}\right]^{1 / \alpha}
$$

Where $p_{t}^{M}$ denotes the price of manufacturing goods.

\section{Resource-based Sector:}

Resource-based industries have often been equated to low-technology and low R\&D. There are two types of resource-based firms in this sector: the natural resource exploitation firms and resource-related firms. In fact, many of them are nowadays intensive in knowledge or capital, and thus can have more value-added than some processed industrial goods, which make them less vulnerable to the price volatility of the primary natural resource. Resource-based firms have one feature in common that they all use resource reserve as an input. So representative resource based firm uses natural resource reserve $R_{t}$ and labor $l_{t}^{R}$ to produce natural resource output, so this sector uses the following technology:

$$
y_{t}^{R}=A_{\tau}^{R}\left(R_{t}\right)^{\alpha}\left(l_{t}^{R}\right)^{1-\alpha}
$$

The representative resource-based firm maximizes the profit and the first order conditions are as following:

$$
l_{t}^{R}=R_{t}\left[(1-\alpha) A_{t}^{R} \frac{p_{t}^{R}}{p_{t}}\right]^{1 / \alpha}
$$

Where $p_{t}^{R}$ denotes the price of manufacturing goods.

Agriculture Sector: the literature about Dutch disease mainly focuses on the developed countries. One of the most important difference between developed and developing countries is the industrial structures. Developing countries are in the process of industrialization, comparing to the mature industrial structure of developed countries. In our model, we introduce the agriculture sector to capture the industry upgrading feature of the developing countries. The representative firm of the agriculture sector uses only labor as the input and uses the following technology to produce output:

$$
y_{t}^{A}=A_{t}^{A}\left(l_{t}^{A}\right)^{1-\alpha}
$$


The representative manufacturing firm maximizes the profit and the first order conditions are as following:

$$
l_{t}^{A}=\left[(1-\alpha) A_{t}^{A} \frac{p_{t}^{A}}{p_{t}}\right]^{1 / \alpha}
$$

Where $p_{t}^{A}$ denotes the price of agriculture goods.

Service sector: in contrast to commodity goods, people must come and visit the country to purchase and consume service goods. The representative firm in the service sector use only labor as input to produce service goods under the following technology:

$$
y_{t}^{N}=A_{t}^{N}\left(k_{t}^{N}\right)^{\alpha}\left(l_{t}^{N}\right)^{1-\alpha}
$$

The first order condition of maximizing profits is

$$
l_{t}^{N}=k_{t}^{N}\left[(1-\alpha) A_{\tau}^{N} \frac{p_{t}^{N}}{p_{t}}\right]^{1 / \alpha}
$$

The price level of tradable goods is given exogenously:

$$
p_{t}^{T}=\gamma_{M} p_{t}^{M}+\gamma_{A} p_{t}^{A}+\gamma_{R} p_{t}^{R}
$$

where $\gamma_{M}, \gamma_{A}$ and $\gamma_{R}$ denote the share of manufacturing, agriculture and natural resource goods in the total tradable goods.

The price level of the economy $p_{t}$ is composed by two parts:

$$
p_{t}=\gamma_{T} p_{t}^{T}+\gamma_{n} p_{t}^{N}
$$

Where $p_{t}^{N}$ is the price of non-tradable goods; $\gamma_{T}$ and $\gamma_{N}$ denotes the share of tradable and non-tradable goods in the total consumption of the household.

The market clearing conditions are the following:

$$
\begin{gathered}
p_{t}^{N} y_{t}^{N}=c_{t}^{N} \\
c_{t}^{T}=p_{t}^{T} y_{t}^{T} \\
p_{t}^{T} y_{t}^{T}=p_{t}^{M} y_{t}^{M}+p_{t}^{R} y_{t}^{R}+p_{t}^{A} y_{t}^{A} \\
p_{t} y_{t}=c_{t}^{N}+c_{t}^{T}
\end{gathered}
$$

Combining (3) and (4), we will get:

$$
\frac{\left(p_{t}^{N}\right)^{-\sigma}}{\left(p_{t}^{T}\right)^{-\sigma}}=\frac{c_{t}^{N}}{c_{t}^{T}}=\frac{p_{t}^{N} y_{t}^{N}}{p_{t}^{M} y_{t}^{M}+p_{t}^{R} y_{t}^{R}+p_{t}^{A} y_{t}^{A}}
$$

Then we can get the price mechanism of the natural resource:

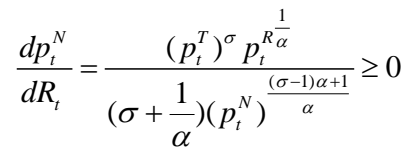

Because the price level of tradable goods is given exogenously, combining (14) and (20) we get $\frac{d p_{t}}{R_{t}} \geq 0$, which means that a resource boom will boost the output level of the economy. This result shows a price transmission mechanism of a resource boom that an increase in natural resource will raise the price level of non-tradable goods, thereby lifting the overall price level of the economy. Combining (12) and (20) we also can get $\frac{l_{t}^{N}}{d R_{t}} \geq 0$, which shows that a resource boom will boost the service sector.

Now we analyze the impact of natural resource increase on the service sector under the market clearing condition.

Combining (11) and (12), we get:

$$
y_{t}^{N}=k_{t}^{N}\left[(1-\alpha) \frac{p_{t}^{N}}{p_{t}}\right]^{\frac{1-\alpha}{\alpha}}=k_{t}^{N}\left[(1-\alpha) \frac{1}{\gamma_{T} p_{t}^{T} / p_{t}^{N}+\gamma_{n}}\right]^{\frac{1-\alpha}{\alpha}}
$$

Combining (20) and (21) we get the following condition: 


$$
\frac{d p_{t}^{N} y_{t}^{N}}{d R_{t}}=\frac{d p_{t}^{N}}{d R_{t}} y_{t}^{N}+\frac{d y_{t}^{N}}{d R_{t}} p_{t}^{N} \geq 0
$$

By (19) we get:

$$
\begin{gathered}
\frac{p_{t}^{N} y_{t}^{N}}{p_{t} y_{t}}=\frac{c_{t}^{N}}{c_{t}^{T}+c_{t}^{N}}=\frac{\left(p_{t}^{N}\right)^{-\sigma}}{\left(p_{t}^{T}\right)^{-\sigma}+\left(p_{t}^{N}\right)^{-\sigma}}=\frac{1}{\left(p_{t}^{T}\right)^{-\sigma}\left(p_{t}^{N}\right)^{\sigma}+1} \\
d \frac{p_{t}^{N} y_{t}^{N}}{p_{t} y_{t}} / d R_{t}=\frac{d\left(p_{t}^{N} y_{t}^{N}\right) / d R_{t}}{p_{t} y_{t}}-\frac{d p_{t} y_{t} / d R_{t}}{\left(p_{t} y_{t}\right)^{2}} \leq 0
\end{gathered}
$$

Result 1: an increase in natural resource will raise the labor and the total output of the service sector, but lower the output share of the service sector in the total economy.

Now we analyze the impact of natural resource increase on the agriculture sector under the market clearing condition.

Because $y_{t}^{A}=\left[(1-\alpha) \frac{p_{t}^{A}}{p_{t}}\right]^{\frac{1-\alpha}{\alpha}}$, then we get:

$$
\frac{d y_{t}^{A}}{d R_{t}}=\left(-\frac{1-\alpha}{\alpha}\right)\left[(1-\alpha) p_{t}^{A}\right]^{\frac{1-\alpha}{\alpha}} p_{t}^{-\frac{1}{\alpha}} \frac{d p_{t}}{d R_{t}} \leq 0
$$

Then we can get:

$$
d \frac{p_{t}^{A} y_{t}^{A}}{p_{t} y_{t}} / d R_{t} \leq 0
$$

By (10), we get:

$$
\frac{d l_{t}^{A}}{d R_{t}}=\left(-\frac{1}{\alpha}\right) A_{t}^{A}\left[(1-\alpha) p_{t}^{A}\right]^{\frac{1}{\alpha}} p_{t}^{-\frac{1}{\alpha}-1} \frac{d p_{t}}{d R_{t}} \leq 0
$$

Result 2: an increase in natural resource will lower the labor and the total output of the agriculture sector and even lower the output share of the sector in the total economy.

Now we analyze the impact of natural resource increase on the manufacturing sector under the market clearing condition.

$$
\begin{gathered}
\frac{d l_{t}^{M}}{d R_{t}}=k_{t}^{M} A_{t}^{M}\left[(1-\alpha) p_{t}^{M}\right]^{1 / \alpha}\left(-\frac{1}{\alpha}\right) p_{t}^{\frac{1-\alpha}{\alpha}} \frac{d p_{t}}{d R_{t}} \leq 0 \\
\frac{d p_{t}^{M} y_{t}^{M}}{d R_{t}}=-\frac{1-\alpha}{\alpha} k_{t}^{M}\left(A_{t}^{M}\right)^{\frac{1}{\alpha}}\left[(1-\alpha) \frac{p_{t}^{M}}{p_{t}}\right]^{\frac{1-\alpha}{\alpha}} \frac{1}{p_{t}} \frac{d p_{t}}{d R_{t}} \leq 0
\end{gathered}
$$

Because $\frac{d p_{t} y_{t}}{d R_{t}} \geq 0$, we get:

$$
d \frac{p_{t}^{M} y_{t}^{M}}{p_{t} y_{t}} / d R_{t}=\frac{1}{p_{t} y_{t}} \frac{d p_{t}^{M} y_{t}^{M}}{d R_{t}}-\frac{p_{t}^{M} y_{t}^{M}}{\left(p_{t} y_{t}\right)^{2}} \frac{d p_{t} y_{t}}{d R_{t}} \leq 0
$$

The same as predicted in the literature of "Dutch disease", an increase in natural resource will lower the labor and the total output of the manufacturing sector and even lower the output share of the sector in the total economy. Then we analyze the impact of natural resource increase on the resource-related sector under the market clearing condition.

$$
d \frac{p_{t}^{R} y_{t}^{R}}{p_{t} y_{t}} / d R_{t}=d \frac{p_{t} y_{t}}{p_{t} y_{t}} / d R_{t}-d \frac{p_{t}^{A} y_{t}^{A}}{p_{t} y_{t}} / d R_{t}-d \frac{p_{t}^{N} y_{t}^{N}}{p_{t} y_{t}} / d R_{t}-d \frac{p_{t}^{M} y_{t}^{M}}{p_{t} y_{t}} / d R_{t}
$$

Thus combining (24), (26) and (30), we will get:

$$
d \frac{p_{t}^{R} y_{t}^{R}}{p_{t} y_{t}} / d R_{t} \geq 0
$$

Thus we will get:

$$
\frac{1}{p_{t} y_{t}} \frac{d p_{t}^{R} y_{t}^{R}}{d R_{t}}-\frac{p_{t}^{R} y_{t}^{R}}{\left(p_{t} y_{t}\right)^{2}} \frac{d p_{t} y_{t}}{d R_{t}} \geq 0
$$


Because $\frac{d p_{t} y_{t}}{d R_{t}} \geq 0$, we get:

$$
\frac{d p_{t}^{R} y_{t}^{R}}{d R_{t}} \geq 0
$$

Because $y_{t}^{R}=\left(R_{t}\right)^{\alpha}\left(l_{t}^{R}\right)^{1-\alpha}$, we also get:

$$
\frac{d l_{t}^{R}}{d R_{t}} \geq 0
$$

An increase in natural resource will raise the labor and the total output of the resource-related sector and also raise the output share of the sector in the total economy. Combining (24),(26), (30) and (31), we will get:

$$
d \frac{p_{t}^{R} y_{t}^{R}+p_{t}^{M} y_{t}^{M}}{p_{t} y_{t}} / d R_{t} \geq 0
$$

Because $\frac{d p_{t} y_{t}}{d R_{t}} \geq 0$, we get:

$$
\frac{d\left(p_{t}^{M} y_{t}^{M}+p_{t}^{R} y_{t}^{R}\right)}{d R_{t}} \geq 0
$$

Result 3: an increase in natural resource will raise the total output of the industrial sectors and also raise the output share of the industrial sectors in the total economy.

Then we analyze the relationship between the resource boom and the economic growth. In each period there is a representative firm (i) who has an opportunity to attempt an innovation. If the firm succeeds, the innovation will create a new version of technology, which is more productive than previous versions. If the firm at t successfully innovates, it will earn the same profit $\Pi^{*}$ under a better technology $A_{t}^{i}=g A_{t-1}^{i}$, where $g>1$. If the firm fails, then there will be no innovation at $t$. In order to innovate, the entrepreneur must conduct the activities of research and development, which will cost the firm the amount of $R D_{t}^{i}$. The probability $\mu_{t}^{i}$ that an innovation occurs in time t depends positively on the productivity-adjusted amount $n_{t}^{i}$, which.

$$
\mu_{t}^{i}=\phi\left(n_{t}^{i}\right) \text {, where } \phi(\mathrm{n})=\lambda^{i}\left(n_{t}^{i}\right)^{\sigma} ; n_{t}^{i}=R D_{t}^{i} / A_{t}^{i}
$$

Where $\lambda^{i}$ is a parameter that reflects the productivity of the R\&D, and for the simplicity, we assume the elasticity $\sigma=0.5$. Thus the marginal product of (productivity-adjusted) $R \& D$ in generating innovations is positive $\left(\phi^{\prime}>0\right)$ but decreasing $\left(\phi^{\prime \prime}<0\right)$.

Because the probability that an innovation occurs in time $t$ is $\mu_{t}^{i}$, so the firm's expected net reward of R\&D is : $\mu_{t}^{i} \Pi_{t}^{*}-R D_{t}^{i}$. The firm will choose the R\&D expenditure $R D_{t}^{i}$ that maximizes the net benefit, which implies that $R D_{t}^{i}$ must satisfy the first-order condition:

$$
\frac{\phi^{\prime}\left(n_{t}^{i}\right) \Pi^{*}}{A_{t}^{i}}=1
$$

We can easily get $\frac{\partial \mu_{t}^{i}}{\partial \lambda^{i}} \geq 0$. We assume the interest rate $r$ is equal to zero. There are two types of capitals: manufacturing capital $k_{t}^{M}$ and resource-based capital $R_{t}$. Our model doesn't explore the capital flow between sectors, so we set $k_{t}^{M}$ to be constant and the interest rate $r$ equal to zero.

The aggregate technology progress is:

$$
A_{\tau}=\alpha_{A} A_{t}^{A}+\alpha_{M} A_{t}^{M}+\alpha_{R} A_{t}^{R}+\alpha_{N} A_{t}^{N}
$$

The literature about "Dutch disease", regards the manufacturing sector as the main driver of economic growth, and resource-based sectors as low-tech. Resource booms may shrink the manufacturing sector, then slow down the economic growth. For simplicity, we have further restricted our attention to the technology progress in manufacturing, resource-based and service 
sectors and assume that there is no technology progress in the agriculture sectors. We assume that: $A_{\imath}^{M}=A_{\imath}^{R}=A_{\imath}^{N}=g A_{t-1}$. Then the aggregate technology progress is:

$$
\begin{aligned}
A_{t}= & \left(\alpha_{M} \mu_{t}^{M} A_{t}^{M}+\alpha_{R} \mu_{t}^{R} A_{t}^{R}+\alpha_{N} \mu_{t}^{N} A_{t}^{N}\right)+ \\
& {\left[\alpha_{A}+\alpha_{M}\left(1-\mu_{t}^{M}\right)+\alpha_{R}\left(1-\mu_{t}^{R}\right)+\alpha_{N}\left(1-\mu_{t}^{N}\right)\right] A_{t-1} }
\end{aligned}
$$

Then the aggregate economic growth is:

$$
g_{t}=\frac{A_{t}}{A_{t-1}}=\alpha_{M}(\mathrm{~g}-1) \mu_{t}^{M}+\alpha_{R}(\mathrm{~g}-1) \mu_{t}^{R}+\alpha_{N}(\mathrm{~g}-1) \mu_{t}^{N}+1
$$

We also assume the technology progresses in each sector will spill over to the overall economies in the next period, so $A_{t-1}$ is the same for the economy. Then the only difference between the probability $\mu_{t}^{i}$ is the parameter of $\lambda^{i}$ :

$$
\mu_{t}^{i}\left(\lambda^{i}\right)==\left(\lambda^{i}\right)^{\frac{1}{1-\sigma}}\left(\frac{\sigma \Pi^{*}}{A_{t}}\right)^{\frac{\sigma}{1-\sigma}}
$$

If the resource boom will boost the economic growth, then the derivative of $g_{t}$ on $R_{t}$ need to be positive:

$$
\frac{d g_{t}}{d R_{t}}=(\mathrm{g}-1)\left[\frac{d\left(\alpha_{M} \mu_{t}^{M}\right)}{d R_{t}}+\frac{d\left(\alpha_{R} \mu_{t}^{R}\right)}{d R_{t}}+\frac{d\left(\alpha_{N} \mu_{t}^{N}\right)}{d R_{t}}\right]
$$

From the previous results we can easily prove the first item $\frac{d\left(\alpha_{M} \mu_{t}^{M}\right)}{d R_{t}} \leq 0$, the second item $\frac{d\left(\alpha_{R} \mu_{t}^{R}\right)}{d R_{t}} \geq 0$, and the $\frac{d\left(\alpha_{N} \mu_{t}^{N}\right)}{d R_{t}} \leq 0$. It shows that it depends on the output ratios $\left(\alpha_{i}\right)$ and the innovation parameters $\lambda_{i}$ of each sector for a resource boom to boost or lower the economic growth. If there is only the agriculture sector in the economy $\left(\alpha_{A}=1\right)$, the derivative of $g_{t}$ on $R_{t}$ is positive and resource boom will definitely boost the economic growth.

$$
\frac{d g_{t}}{d R_{t}}=(\mathrm{g}-1) \mu_{t}^{R} \frac{d \alpha_{R}}{d R_{t}}
$$

Result 4: Developing countries with a less developed manufacturing sector may enjoy a "resource blessing" with a resource boom, and there exists a converse U relationship between a resource boom and economic growth.

\section{Conclusions}

This study shows that economies may benefit from a resource boom in both theoretical and empirical sense. We present a multi-sector model of a local economy with a resource-based sector and R\&D arbitrage based on Schumpeter's process of creative destruction. A resource boom will alter the industrial structure of the local economy. If the initial industrial structure is suitable, such as a big agriculture sector or a high efficiency of R\&D in resource-based sectors, growth results may come from the "structure upgrading incurred by a resource boom. Our model does not deny the "Dutch disease", but extends the literature by incorporating the transmission mechanism of industrial structure. If there is a big agriculture share in the local economy, it is lucrative for the economy to $R \& D$. If the local economy is highly resource dependent, it is not lucrative to $R \& D$, therefore the economic growth will slow down.

\section{Acknowledgements}

The project is supported by Chinese National Natural Science Foundation of China under Grant No. 71563035, Natural Science Foundation of Inner Mongolia Education Department under Grant No. NJZZ003 and Chinese Education Ministry Foundation under Grant No. IRT1258. 


\section{References:}

[1] A Lvarez, Luis J.; Hurtado, Samuel; S A Nchez, Isabel and Thomas, Carlos. "The Impact of Oil Price Changes On Spanish and Euro Area Consumer Price Inflation." Economic Modelling, 2011, 28(1), pp. 422-31.

[2] Bardini, Carlo. "Without Coal in the Age of Steam: A Factor-Endowment Explanation of the Italian Industrial Lag Before World War I." The journal of economic history, 1997, 57(03), pp. 633-53.

[3] Benjamin, Nancy C.; Devarajan, Shantayanan and Weiner, Robert J. "The 'Dutch'Disease in a Developing Country: Oil Reserves in Cameroon." Journal of Development Economics, 1989, 30(1), pp. 71-92.

[4] Benkhodja, Mohamed. "Monetary Policy and the Dutch Disease in a Small Open Oil Exporting Economy." 2011.

[5] Stijns, Jean-Philippe C. "Natural Resource Abundance and Economic Growth Revisited." Resources policy, 2005, 30(2), pp. 107-30.

[6] Torvik, Ragnar. "Learning by Doing and the Dutch Disease." European economic review, 2001, 45(2), pp. 285-306.

[7] Van der Ploeg, Frederick. "Natural Resources: Curse Or Blessing?" Journal of Economic Literature, 2011, 49(2), pp. 366-420.

[8] Van der Ploeg, Frederick and Poelhekke, Steven. "Volatility and the Natural Resource Curse." Oxford economic papers, 2009, 61(4), pp. 727-60. 